Prevalence Of Hiv/Hsv-2 Co-Infection Was Higher In Female Adults Than Female Adolescents (17.1 [95\% Ci:13.6-21.0] Versus 3.4 [95\% Ci:1.1-7.8]).

Conclusion High Incidence Rate Among Persons With Indeterminate Results Underscores The Public Health Concerns For Hsv-2 Spread And Underreporting Of The Hsv-2 Burden. Careful Consideration Is Needed When Interpreting Hsv-2 Serology Results In These Settings.

\section{LB5.37 CANCER AND OPPORTUNISTIC INFECTIONS AMONG THE PEOPLE LIVING WITH AIDS ON ART IN EASTERN NEPAL}

Ram Sharan Mehta. Medical-Surgical Nursing Department - B.P. Koirala Institute of Health Sciences, Dharan, Nepal

\subsection{6/sextrans-2017-053264.652}

Introduction Opportunistic infections (OIs) are more frequent and severe because of immune-suppression in $\mathrm{HIV}$-infected persons, and are the major clinical manifestation of HIV patients. Cancer is a significant cause of mortality and morbidity in people infected with HIV; in fact $30 \%$ to $40 \%$ will develop a malignancy during their lifetime. The objective of this study was to find out the prevalence of Opportunistic Infections (OI) and Cancer among the PLWA on ART in eastern of Nepal.

Methods Descriptive cross-sectional research design was used to carry out the study. The PLWA receiving ART residing in eastern Nepal constitute the population of the study. Using convenient sampling technique 75 subjects were selected for study during the period of $15^{\text {th }}$ June 2014 to $30^{\text {th }}$ July 2014 of six weeks.

Results Majority of the PLWA (52.65\%) were of age group of 35-45 years, Male (62.7\%) and Hindu (81.3\%). Among the PLWA about $13 \%$ were illiterate; $18.7 \%$ were farmer, $13.3 \%$ house wife, $10.7 \%$ were driver and $9.7 \%$ were labour. Most of the respondents (60\%) were from Sunsari District and $61.3 \%$ belongs to rural areas. The common OIs found were Pulmonary Tuberculosis (33.3\%), extra Pulmonary TB (14.7\%), Oral Thrush (30.7\%), fungal infection (22.7\%), Herpes Zoster (14.7\%) and Hepatitis-C (18.7\%); whereas regarding Cancer it was found that $22.7 \%$ had Lymphandopathy, 18.7\% had Skin Cancer and 2.7\% had Kaposi-Sarcoma.

Conclusion It can conclude that the Opportunistic Infections among PLWA were Tuberculosis, Oral Thrush, Fungal infection, Hepatitis-C, and Herpes Zoster; whereas, cancer of Lymphnode, skin cancer and Kaposi-Sarcoma was found among the PLWA receiving ART in eastern Nepal.

\section{Policy, Advocacy, and Community Engagement in STI/HIV Research}

\section{P6.01 KNOWLEDGE AND ATTITUDE TOWARDS HIV VACCINE TRIAL CONCEPTS AMONG YOUTH OF MANGALORE CITY}

Asmin Sha. Al IQBAL Hospital, Thrissur, India

10.1136/sextrans-2017-053264.653

Introduction AIDS vaccine is seen as the ultimate prevention tool that will complement the existing prevention strategies in place. Patients participate in HIV vaccine trials with hope that developing a safe and effective AIDS vaccine is possible. To begin to understand adolescent attitudes to these complex issues, and inform our future work with adolescents in HIV vaccine trials, we undertook a formative study examining attitudes towards such trials, potential motivating factors and hypothetical willingness to participate, among youth.

Methods A self-administered, facilitated questionnaire was administered to 277 students in pre university colleges, Mangalore, India from August 2012 to February 2013. The questionnaire explored general HIV knowledge, perception of adolescent risk, knowledge of vaccine concepts, willingness to participate in future vaccine trials, perceived personal and social harms and benefits associated with participation as well as barriers and facilitators to participating in future HIV vaccine trials.

Results 277 college-going youth provided consent to participate, and if under 18 , we also obtained written consent from a parent. Of the 241 participants who responded to the question on HIV testing, 10\% indicated that they have tested for HIV. Of the majority $(57 \%)$ of participants believed that parents should give permission for their child's HIV test while most of the participants (84\%) believed that parents should know the HIV status of their child.

Conclusion The youth report high degrees of willingness to participate in HIV vaccine trials. This may be related to the high levels of adolescent HIV risk perception. The spectre of HIV infection looms regardless of age group, and adolescents are no exception. Indeed, public health practice would seem to say that effective vaccination of this subgroup above all would result in the greatest reduction in new infections.

\section{P6.02 A REGIONAL ADVOCACY AGENDA ON TRANSGENDER HEALTH AND SEXUAL HEALTH AMONG TRANSGENDER PEOPLE IN THE ISEAN REGION}

RN Cortes. The Philippine Ngo Council on Population, Health and Welfare, Inc., Pasay City, Philippines

\subsection{6/sextrans-2017-053264.654}

Introduction The ISEAN-Hivos Program (IHP) is a regional Global Fund AIDS grant focused on community systems strengthening (CSS) among males having sex with males (MSM) and transgender (TG) organisations in Indonesia, Malaysia, Philippines and Timor Leste. One of the strategies of the program is to disaggregate transgender people from MSM, and be recognised as a unique key affected population. Methods Given the lack of evidence-based data to guide development partners, government agencies and donors to develop transgender-specific health interventions, IHP through the ISEAN Secretariat conducted the TransISEAN: Regional Community Workshop on Health, SOGIE and Rights among Transgender People in the ISEAN Region last August 14-16, 2015 in Kuala Lumpur, Malaysia. The objective of the regional consultation is to develop a regional advocacy agenda for trans people that is prioritised on the key areas of trans health and services, and trans research/surveillance.

Results The agreed upon advocacy agenda on trans health research/surveillance prioritised the following: A mapping of current organisations and available services including CSOs, health care service providers, trans communities, etc. Continuously push the health ministries to conduct transgender-specific 